\title{
Spinal Injuries as a Result of Sporting Accidents
}

\author{
J. R. Silver MB, BS, FRCP Ed. \& Lond.
}

National Spinal Injuries Centre Stoke Mandeville Hospital, Aylesbury Bucks, England

Injuries of the spinal cord are becoming more frequent as leisure activities increase. There have been 7700 admissions to Stoke Mandeville Hospital. There have been 38 gymnastic injuries, 67 rugby injuries and 16 trampolining accidents. The vast majority were injuries to the cervical spine, the ages were around the age of 20 .

\section{Rugby}

Between 1952 and 1982, 67 players have been studied (63 Rugby Union, 2 Rugby League and 2 American Football) who sustained serious injuries of their spine. The injuries fell predominantly on the lower cervical spine. Forty-eight of the players sustained serious injuries of the spinal cord leading to paralysis and total incapacity. There appears to be an increase in these injuries in recent years, particularly amongst schoolboys and in the tackle and maul ruck situations. The causes of these injuries have been analysed in relation to the neurological damage and the way the game is being played. The measures that have been taken to change the laws and attitudes have been outlined. (Silver JR 1972, Silver JR 1979, Silver JR 1975, Silver JR 1984).

\section{Trampolining}

Between 1963 and 1978, 16 trampolining accidents were studied, 15 with serious spinal injuries and 1 with facial lacerations. The injuries fell in the lower cervical spine leading to paralysis and total incapacity. These injuries have decreased in recent years as a result of better training and coaching methods. The cases of these injuries were analysed in relation to the neurological damage and where the sport is being organised. The measures taken to change the attitudes of the coaches have been outlined. (Silver JR, Silver DD \& Godfrey JJ 1986).

\section{Gymnastics}

Between 1945 and 1985, 38 gymnastic accidents were studied. The injuries fell predominantly on the lower cervical spine. There were 3 lumbar injuries. The 
majority of the gymnasts sustained serious injuries leading to paralysis and total incapacity. There appears to have been an increase in these injuries in recent years. 18 of the accidents were the result of a somersault. (Silver JR, Silver DD \& Godfrey JJ 1986).

\section{References}

SILVER JR 1972 Neck Injuries: the constant threat to rugger players. General Practitioner, 1:10-11. SILVER JR 1979 Rugby injuries to the cervical cord. British Medical Journal 1:192-193.

SILVER JR 1975 Rugby injuries of the spine. In: O'Connell TCJ, ed. Injuries in rugby football and other team sports. Dublin: Irish Rugby Football Union, 110-5.

SILVER JR 1984 Injuries of the spine sustained in rugby. British Medical Journal 288:37-43.

SILVER JR, SILVER DD \& GodFREY JJ 1986 Trampolining injuries of the spine. Injury 17:117124.

SILVER JR, SILVER DD, \& GODFREY JJ 1986 Injuries of the spine sustained at gymnastic activities. British Medical Journal. 293: 861-3. 